\title{
Photoluminescence characteristics of soft PZT 53/47 ceramic doped at $A$ and/or $B$ sites
}

\author{
M. D. DURRUTHY-RODRÍGUEZ ${ }^{a, b}$, J. J. GERVACIO-ARCINIEGA ${ }^{c}$, \\ M. HERNÁNDEZ-GARCÍA ${ }^{a, b}$, J. M. YÁÑEZ-LIMÓN ${ }^{d, *}$ \\ ${ }^{a}$ Universidad Nacional Evangélica, Calle Libertador No. 18, San Carlos, \\ Santo Domingo, Distrito Nacional, CP 10203, República Dominicana \\ ${ }^{b}$ Departamento de Física Aplicada, Instituto de Cibernética, Matemática y Física, \\ CITMA, 15 \# 551, Vedado, La Habana, CP 10400, Cuba \\ ${ }^{c}$ Catedrático CONACYT-Facultad de Ciencias Físico Matemáticas, Benemérita \\ Universidad Autónoma de Puebla, AP 1152, Puebla, Pue., 72000, México \\ ${ }^{d}$ CINVESTAV-Unidad Querétaro del IPN, Libramiento Norponiente 2000, Fracc. \\ Real de Juriquilla, CP 76230, Santiago de Querétaro, Querétaro, México
}

Received: October 12, 2017; Revised: January 18, 2018; Accepted: January 29, 2018

(C) The Author(s) 2018. This article is published with open access at Springerlink.com

\begin{abstract}
This study presents the photoluminescence characteristics of the PZT 53/47 system doped at A and/or B sites, with $\mathrm{Nb}$ (PZTN), La (PLZT), and Nb-La (PLZTN) in the concentration range from 0.2 to 1.0 molar fraction. The intensity of the emission bands of the system PZTN is two orders higher than the intensity of the emission bands of the systems PLZT and PLZTN, and these emission bands are located at $1.73 \mathrm{eV}(718 \mathrm{~nm}), 2.56 \mathrm{eV}(485 \mathrm{~nm})$, and $2.93 \mathrm{eV}(424 \mathrm{~nm})$. The origin of the luminescence in these systems is associated with lead and oxygen vacancies produced during the sintering process. The results from X-ray diffraction (XRD) show a mixture of rhombohedral and tetragonal phases. The system PZTN shows a higher tetragonal phase concentration, while PLZT and PLZTN systems show a higher rhombohedral phase concentration. The cell volume shows an increase with dopant concentration only in the case of the PLZTN system. The band gap energy shows a small variation in the PZTN and PLZTN cases around 3.0 eV, a close value to the band gap energy of the pure PZT 53/47 sample. The system PLZT shows an increasing behavior until $4.41 \mathrm{eV}$ for the higher dopant concentration.
\end{abstract}

Keywords: photoluminescence; PZT ceramics; band structure; X-ray diffraction (XRD)

\section{Introduction}

$\mathrm{Pb}(\mathrm{Zr}, \mathrm{Ti}) \mathrm{O}_{3}$ (PZT) is the most important piezoelectric material, which has been used in various electronic

* Corresponding author.

E-mail: jmyanez@cinvestav.mx devices. The PZT family as $\mathrm{BaTiO}_{3}$ and its solid solution with other perovskite $\mathrm{ABO}_{3}$ exhibit high dielectric constant and other advantageous properties. Lanthanide doped $\mathrm{ABO}_{3}$ gains great interest on searching new ferroelectric thin films with fatigue-free polarization properties for nonvolatile random access memories. La and $\mathrm{Nb}$ doped $\mathrm{ABO}_{3}$ can give place to excellent electrical 
properties such as high fatigue resistance, good remnant polarization, fast switching speed, high Curie temperature, large spontaneous polarization, and small coercive field. These properties are desirable to reach in lead-free systems like bismuth titanate [1-3].

Although some lead-free ferroelectric systems have begun to show properties equivalent to those shown by PZT, it exhibits even higher values in important multifunctional electrical properties such as ferroelectric, dielectric, piezoelectric, pyroelectric, and electrooptic properties. It can be used to fabricate various microelectronic and optoelectric devices including nonvolatile ferroelectric random access memories, microsensors and microactuators, integrated capacitors, and electrooptic modulators $[1,2,4]$. Recently, photoluminescence (PL) properties originated from defects in perovskite structure in PZT materials are attractive due to their potential integrated photoluminescent ferroelectric device applications [5-10]. This work studies the photoluminescence in PZT ceramics near morphotropic phase boundary doped with $\mathrm{Nb}, \mathrm{La}$, and $\mathrm{Nb}-\mathrm{La}$.

\section{Experimental procedure}

The general formula of the materials studied was $\mathrm{Pb}_{1-3 x / 2} \mathrm{La}_{x}\left(\mathrm{Zr}_{53} \mathrm{Ti}_{47}\right)_{1-y} \mathrm{Nb}_{y} \mathrm{O}_{3}(x, y=0,0.002,0.004$, $0.006,0.008,0.01)$; in particular for double substitution $x=y$, it can be abbreviated, as shown in Table 1 .

The samples were prepared by conventional processing method using mixed oxide and carbonate powders $\mathrm{PbCO}_{3}$ (98\%, BDH), $\mathrm{ZrO}_{2}$ (99\%, Merck), $\mathrm{TiO}_{2}$ (99\%, Riedel de Haën), $\mathrm{Nb}_{2} \mathrm{O}_{5}$ (spectroscopy purity, JMC), and $\mathrm{La}_{2} \mathrm{O}_{3}$ (spectroscopy purity, Merck). The mixture of constituent powders in stoichiometric form was milled in ethanol with an agate mortar for $90 \mathrm{~min}$, dried at $100{ }^{\circ} \mathrm{C}$; calcination was made at $950{ }^{\circ} \mathrm{C}$ for $90 \mathrm{~min}$. Subsequently the samples were milled and conformed in discs measuring $20 \mathrm{~mm}$ in diameter pressed at approximately $250 \mathrm{MPa}$, and then sintered at $1250{ }^{\circ} \mathrm{C}$ for $100 \mathrm{~min}$.

Table 1 Stoichiometric composition for each PZT system studied

\begin{tabular}{lcl}
\hline & $\mathrm{Pb}_{1-3 x / 2} \mathrm{La}_{x}\left(\mathrm{Zr}_{53} \mathrm{Ti}_{47}\right)_{1-y} \mathrm{Nb}_{y} \mathrm{O}_{3}$ \\
\hline$y=0$ & $x=0$ & $x=y=0,0.002$, \\
$x=0,0.002,0.004$, & $y=0,0.002,0.004$, & $0.004,0.006,0.008$, \\
$0.006,0.008,0.01$ & $0.006,0.008,0.01$ & 0.01 \\
\hline $\mathrm{PLZT} \mathrm{53/47/0.2}$ & PZTN 53/47/0.8 & PLZTN 53/47/0.4 \\
for $x=0.002$ & for $y=0.008$ & for $x=y=0.004$ \\
\hline
\end{tabular}

The crystalline structure of the samples was analyzed using a Rigaku DMax-2100 diffractometer with $\mathrm{Cu} \mathrm{K} \alpha$ radiation $(\lambda=1.5418 \AA)$ and $2 \theta$ range from $15^{\circ}$ to $60^{\circ}$, working at $30 \mathrm{kV}$ and $16 \mathrm{~mA}$.

Photoluminescence (PL) was measured with a Jobin Yvon Horiba Fluoromax-3 spectrometer using the excitation bands at 273,373 , and $457 \mathrm{~nm}$. The absorption spectra were obtained with a spectrometer UV-Vis Ocean Optics QE65000 using diffuse reflectance measurements; the data was processed by the Kubelka-Munk function:

$$
\begin{gathered}
F\left(R_{\infty}^{\prime}\right)=\frac{\left(1-R_{\infty}^{\prime}\right)^{2}}{2 R_{\infty}^{\prime}}=\frac{\alpha}{S} \\
R_{\infty}^{\prime}=\frac{R_{\infty}(\text { sample })}{\left.R_{\infty} \text { (standard }\right)}
\end{gathered}
$$

where $R_{\infty}=I / I_{0}$ is the diffuse reflectance at one wavelength from an opaque sample with infinite thickness $(>2 \mu \mathrm{m}), 0<R_{\infty}<1, \alpha$ is the absorbance $\left(\mathrm{cm}^{-1}\right)$, and $S$ is the scattering factor which is assumed to be independent of the wavelength for grain size greater than the wavelength of the light [11-13]. The square of the product of Kubelka-Munk function $F(R)$ and energy photon $(h v)$ as a function of photon energy $(h v)$ permits the experimental determination of the band gap energy $E_{\mathrm{g}}$, with the assumption that the samples have direct band gap [13-15]. All characterizations were performed at room temperature.

\section{Results and discussion}

\section{1 Structure analysis}

The phase identification was performed with X-ray powder diffraction (XRD) technique. The calculation of the reticular parameters was obtained with a precision of $0.001 \AA$. The XRD patterns of the crystalline powders show the tetragonal and rhombohedral PZT phases. Small concentration of spurious phase (pyrochlore) is detected, which shows a small diffraction peak at $28^{\circ}$. XRD results for all compositions are shown in Fig. 1.

The results obtained agree with those reported for the PZT system at the morphotropic phase boundary [16], where the rhombohedral and tetragonal phases coexist; a similar composition was analyzed in this work. In all compositions, the mixture of phases is present, varying the concentration thereof. The system PZTN shows an increasing tetragonal phase concentration with increasing niobium concentration, while PLZT and PLZTN systems show an increased concentration of 


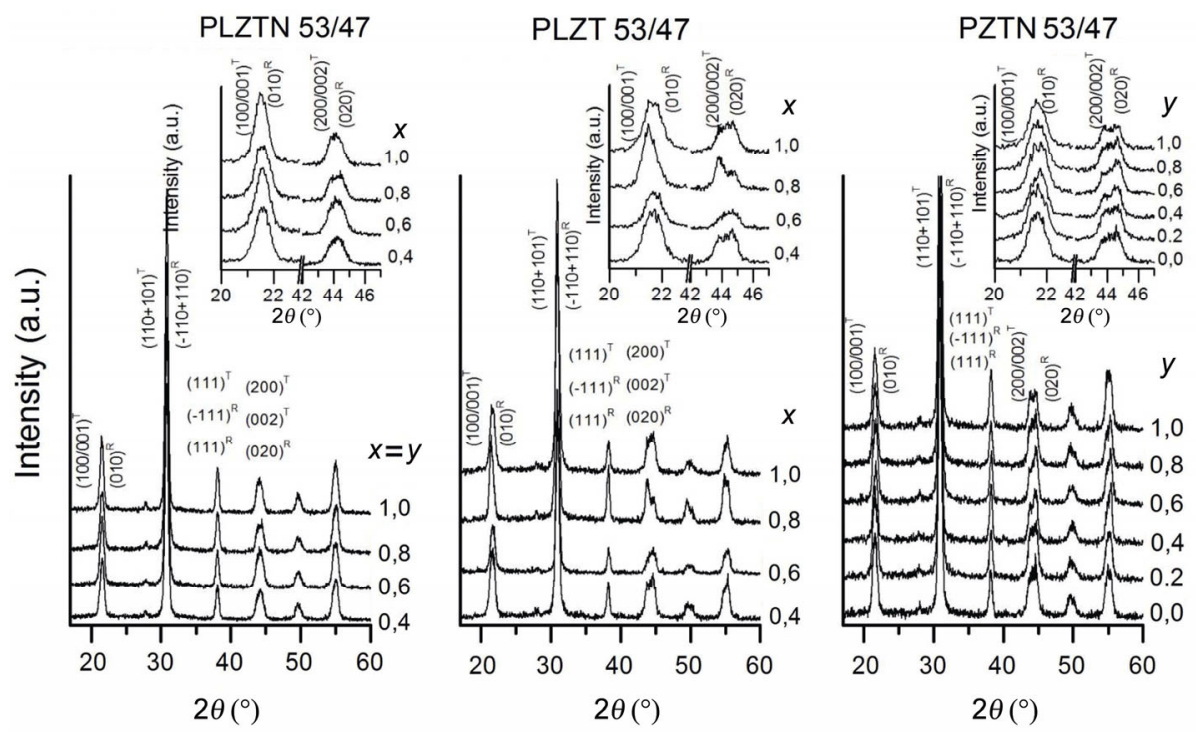

Fig. 1 XRD patterns of PLZTN, PLZT, and PZTN samples at room temperature.

the rhombohedral phase when lanthanum concentration is increased.

The data in Fig. 1 shows the tetragonal phase peaks (100), (001), (200), and (002) and the rhombohedral phase peaks (010) and (020). These figures suggest that PLZT and PLZTN samples show higher concentration of rhombohedral phase.

The determination of cell parameters was performed manually using the peaks corresponding to (200) and (002) for the tetragonal phase and (020) and (120) for the rhombohedral phase. The method used was to perform a deconvolution of the corresponding experimental diffraction peaks and adjust them using Gaussian functions. The $c / a$ ratio of unit cell shows a maximum for the dopant molar fraction 0.6; this result is different from the classical behavior, in which some authors have reported a decreasing behavior with dopant concentration [16-18].

The change of lattice parameters with the dopant concentration is shown in Fig. 2. For samples doped with niobium (PZTN and PLZTN), the lattice parameter of the rhombohedral phase is between $a$ and $c$ lattice parameters of tetragonal phase; however, for PLZT, the lattice parameter of rhombohedral phase is bigger than $a$ and $c$ lattice parameters of the tetragonal phase.

Figure 3 shows the evolution of cell volume as a function of the dopant concentration. In general, the rhombohedral phase shows a higher volume, and the PLZT system shows an increasing behavior with dopant concentration. The volume of system PLZT is around 14\% higher than those of systems PZTN and
PLZTN.

Table 2 shows the cell volume, lattice parameter, and the tetragonality degree of the samples for each molar concentration of dopant.

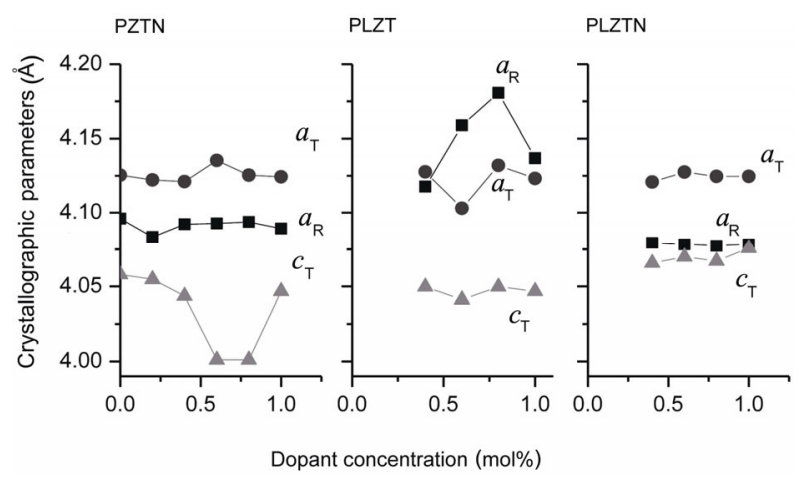

Fig. 2 Lattice parameters for different type of substitution. Note the major influence of lanthanum rather than niobium in the lattice parameter variations.

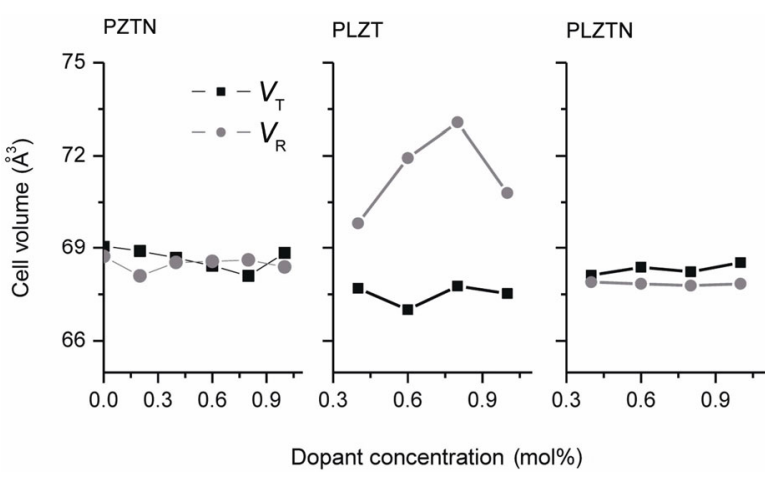

Fig. 3 Crystallographic cell volume considering both crystalline structures present, $V_{\mathrm{T}}$ (tetragonal volume) and $V_{\mathrm{R}}$ (rhombohedral volume) for analyzed samples. 
Table 2 Lattice parameters and cell volume for the PZT 53/47 doped at different concentration of $\mathrm{La}^{3+}$ and $\mathrm{Nb}^{5+}$, at room temperature

\begin{tabular}{|c|c|c|c|c|c|c|c|}
\hline \multirow{2}{*}{ Ceramic type } & \multirow{2}{*}{$\begin{array}{l}\text { Molar fraction } \\
\quad(\mathrm{mol} \%)\end{array}$} & \multicolumn{2}{|c|}{ Cell volume $\left(\AA^{3}\right)$} & \multicolumn{4}{|c|}{ Lattice parameter } \\
\hline & & Tetragonal & Rhombohedral & $a_{\mathrm{R}}(\AA)$ & $c_{\mathrm{T}}(\AA)$ & $a_{\mathrm{T}}(\AA)$ & $c / a$ \\
\hline \multirow{6}{*}{ PZTN } & 0.0 & 67.93 & 68.72 & $4.096\left(\alpha=89.94^{\circ}\right)$ & 4.125 & 4.058 & 1.017 \\
\hline & 0.2 & 67.77 & 68.09 & $4.084\left(\alpha=89.49^{\circ}\right)$ & 4.122 & 4.055 & 1.017 \\
\hline & 0.4 & 67.38 & 68.53 & $4.092\left(\alpha=90.44^{\circ}\right)$ & 4.121 & 4.044 & 1.030 \\
\hline & 0.6 & 66.20 & 68.56 & $4.093\left(\alpha=89.83^{\circ}\right)$ & 4.135 & 4.001 & 1.034 \\
\hline & 0.8 & 66.04 & 68.61 & $4.094\left(\alpha=89.12^{\circ}\right)$ & 4.125 & 4.001 & 1.031 \\
\hline & 1.0 & 67.54 & 68.38 & $4.089\left(\alpha=89.71^{\circ}\right)$ & 4.124 & 4.047 & 1.019 \\
\hline \multirow{4}{*}{ PLZT } & 0.4 & 67.70 & 69.82 & $4.118\left(\alpha=89.48^{\circ}\right)$ & 4.128 & 4.050 & 1.019 \\
\hline & 0.6 & 67.01 & 71.92 & $4.159\left(\alpha=89.43^{\circ}\right)$ & 4.103 & 4.041 & 1.015 \\
\hline & 0.8 & 67.77 & 73.07 & $4.181\left(\alpha=89.45^{\circ}\right)$ & 4.132 & 4.050 & 1.020 \\
\hline & 1.0 & 67.53 & 70.80 & $4.137\left(\alpha=89.46^{\circ}\right)$ & 4.123 & 4.047 & 1.019 \\
\hline \multirow{4}{*}{ PLZTN } & 0.4 & 68.11 & 67.89 & $4.080\left(\alpha=89.41^{\circ}\right)$ & 4.121 & 4.066 & 1.0136 \\
\hline & 0.6 & 68.37 & 67.84 & $4.078\left(\alpha=89.39^{\circ}\right)$ & 4.128 & 4.070 & 1.0141 \\
\hline & 0.8 & 68.23 & 67.78 & $4.077\left(\alpha=89.38^{\circ}\right)$ & 4.125 & 4.067 & 1.0141 \\
\hline & 1.0 & 68.52 & 67.84 & $4.078\left(\alpha=89.34^{\circ}\right)$ & 4.125 & 4.076 & 1.0120 \\
\hline
\end{tabular}

\section{2 Optical properties, PL emission, and forbidden gap}

Figures 4-6 show the PL spectra of systems PZTN, PLZT, and PLZTN, when fixing the excitation bands (EB) at $457 \mathrm{~nm}(2.74 \mathrm{eV}), 373 \mathrm{~nm}(3.36 \mathrm{eV})$, and 273 $\mathrm{nm}(4.59 \mathrm{eV})$, respectively. These figures show the PL spectra of the system PZTN in the inset, for each excitation band. For PLZT and PLZTN, four emission bands are observed; however, for PZTN, only three very well defined bands appear. While for PLZT and PLZTN, the emission bands are broad and their intensity is one or two orders smaller than PZTN [11]. These important differences in the emission spectra suggest that recombination mechanisms in these sets of samples are different.

For PZTN, the emission bands are around $1.73 \mathrm{eV}$ (718 nm, lowest energy region, inset in Fig. 5) when excited by $373 \mathrm{~nm}$. The second is around $2.55 \mathrm{eV}$ (486 nm, inset in Fig. 4) excited by $457 \mathrm{~nm}$ which shows a higher intensity, and the third is around $2.93 \mathrm{eV}$ (424 nm, highest energy region, inset in Fig. 6) excited by $273 \mathrm{~nm}$.

Samples PLZT and PLZTN show the next emission bands: the first appears at around $1.76-1.87 \mathrm{eV}$ (706-664 nm, lowest energy region) excited by 457 and $373 \mathrm{~nm}$ (Figs. 4 and 5), and this band shows the lowest intensity; the second band is around $2.32-2.55 \mathrm{eV}$ (486-534 nm) excited by $457 \mathrm{~nm}$, and this band shows the highest intensity. The third band is broadened from 2.5 to $3.2 \mathrm{eV}$ with a maximum around $3 \mathrm{eV}$, excited by $373 \mathrm{~nm}$ (Fig. 5). When exited with $273 \mathrm{~nm}$, two emission bands are observed (Fig. 6), one at $2.9 \mathrm{eV}$ whose intensity is lower than excitation at $373 \mathrm{~nm}$ (for doped PZT) and the other emission band at around $3.94 \mathrm{eV}(315 \mathrm{~nm})$ only for doped PZT.

The bands do not show any notable shift in the

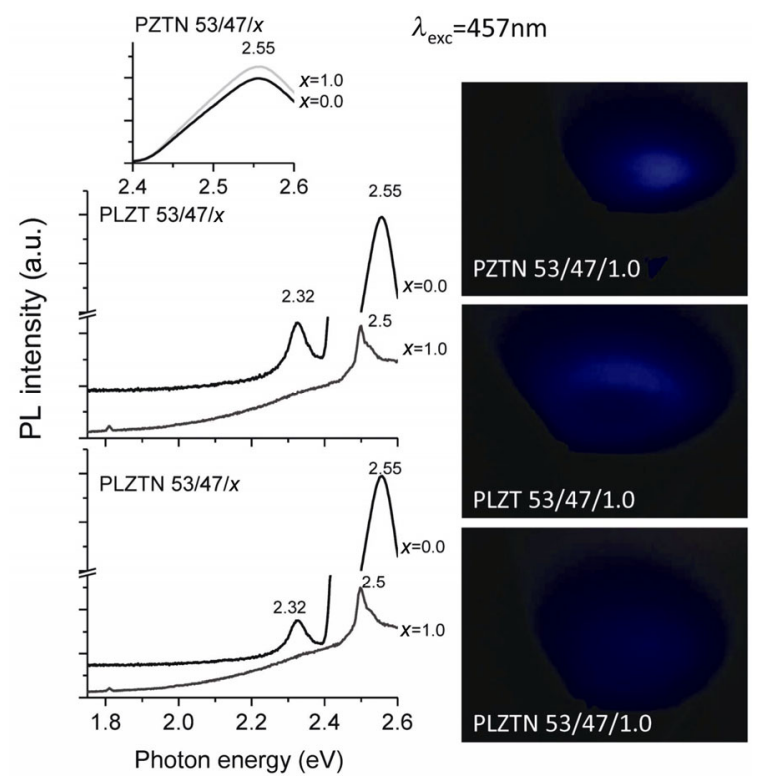

Fig. 4 PL spectra for $\mathrm{Pb}_{1-3 x / 2} \mathrm{La}_{x}\left(\mathrm{Zr}_{53} \mathrm{Ti}_{47}\right)_{1-y} \mathrm{Nb}_{y} \mathrm{O}_{3}$ for $x$, $y=0,0.01$, excited at $457 \mathrm{~nm}$. The inset shows the spectra of PZTN system [11]. 


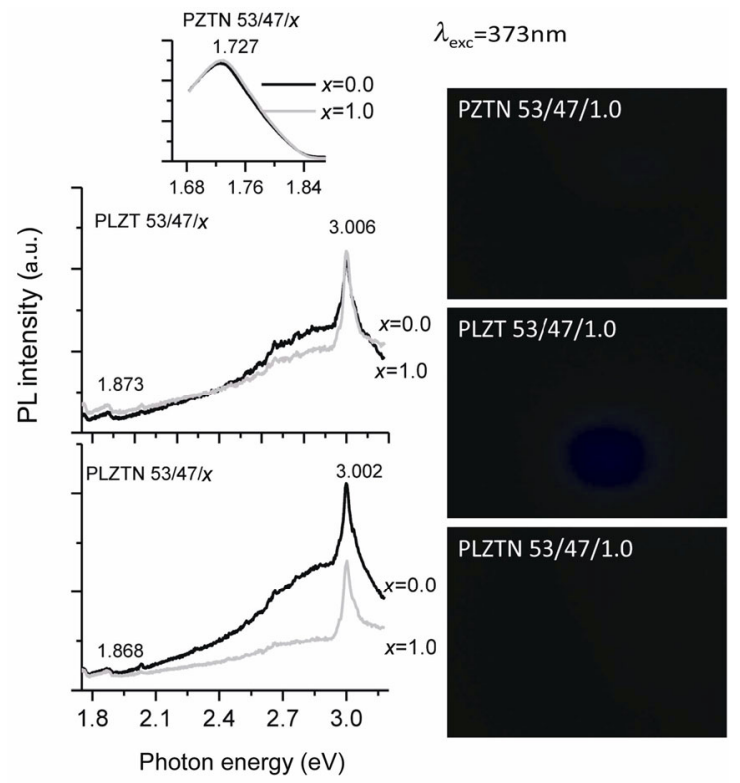

Fig. 5 PL spectra for PLZT, PLZTN, and PZTN 53/47 systems for different dopant concentration excited at $373 \mathrm{~nm}$.

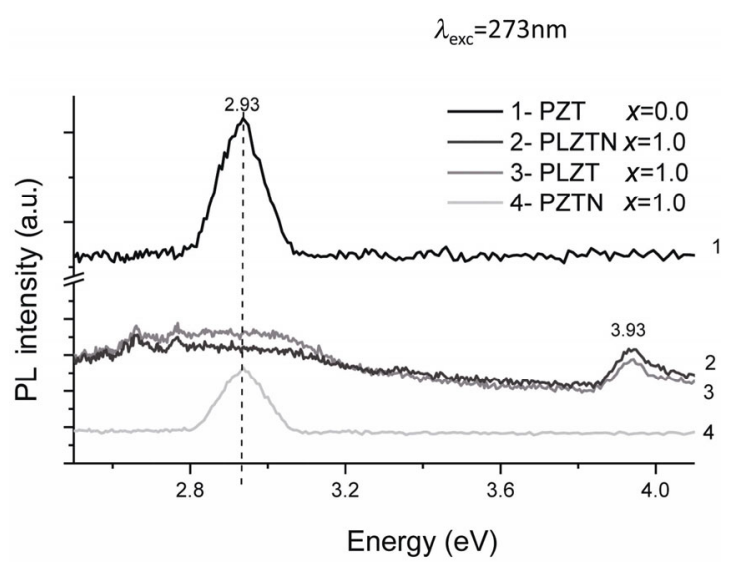

Fig. 6 PL spectra for the same samples in Fig. 4 but exited at $273 \mathrm{~nm}$.

maximum position for increased dopant concentration; however, the emission intensity shows a decreasing behavior with it.

It is important to note that in the PZT polycrystalline samples without dopant, the three or four well-resolved emission bands are also shown. This does not agree with other reports $[5,6,8,19]$, where the emission for polycrystalline PZT is very low and broad or absent, except where the concentration of disordered structure clusters of type $\mathrm{TiO}_{5}$ increases in the samples, prompting broad emission band composed by three emission bands centered at 430,600, and $730 \mathrm{~nm}$, when the samples were excited with $355 \mathrm{~nm}$ [5]. As other authors have pointed out the photoluminescence is strongly affected by the distortion of crystal structure. In this case, perovskite structure is deformed by substituting both $\mathrm{A}$ and B sites. Although the three groups of samples show similar structures, the existence of higher concentration of tetragonal phase in PZTN seems to favor the selective photoluminescence effect that happens in these samples, being higher than the one reported for La doped PZT [8].

In this work, the experimental band gap was estimated through the absorption spectra that were obtained by diffuse reflectance using the Kubelka-Munk equation. The experimental band gap values show some variation for the reported values, from 3.16 to $3.2 \mathrm{eV}$ for polycrystalline samples and 2.90 to $3.07 \mathrm{eV}$ for amorphous samples $[5,20]$.

Table 3 shows the $E_{\mathrm{g}}$ values for the systems as follows: the values for PLZT are located between 2.75 and $4.41 \mathrm{eV}$, and the values for PLZTN and PZTN are located between 2.75 and $3.13 \mathrm{eV}$, so the most remarkable difference in $E_{\mathrm{g}}$ values is for the PLZT series.

The curves $(F(R) * h v)^{2}$ vs. photon energy are presented for the PLZT, PLZTN, and PZTN in Fig. 7. The experimental results show that the incorporation of La in PZT increases its band gap [20] and results in better transparency for electrooptic applications, which is comparable with previous experimental results [21].

The increase of the band gap depends on the number of symmetry elements and the change in the structure. The results show that dopants $\mathrm{La}^{3+}$ and $\mathrm{Nb}^{5+}$ favor the presence of rhombohedral and tetragonal structures, respectively. The number of symmetry elements changes from 6 to 8, and the energy of the band gap diminishes for tetragonal structure [20], like in our system. In accordance with theoretical results $[20,22,23]$, the

Table 3 Experimental optical band gap energy at room temperature for the PZT 53/47 doped with $\mathrm{La}^{3+}$ and $\mathrm{Nb}^{5+}$

\begin{tabular}{cccc}
\hline \multirow{2}{*}{$\begin{array}{c}\text { Dopant concentration } \\
(\text { mol\%) }\end{array}$} & \multicolumn{3}{c}{$E_{\mathrm{g}}(\mathrm{eV})$} \\
\cline { 2 - 4 } & PLZT 53/47 & PLZTN 53/47 & PZTN 53/47 \\
\hline 0.0 & 2.75 & 2.75 & 2.75 \\
0.2 & 3.14 & 3.13 & 3.10 \\
0.4 & 3.27 & 3.07 & 3.11 \\
0.6 & 3.04 & 2.95 & 2.76 \\
0.8 & 4.25 & 3.11 & 2.88 \\
1.0 & 4.41 & 2.94 & 2.69 \\
\hline
\end{tabular}



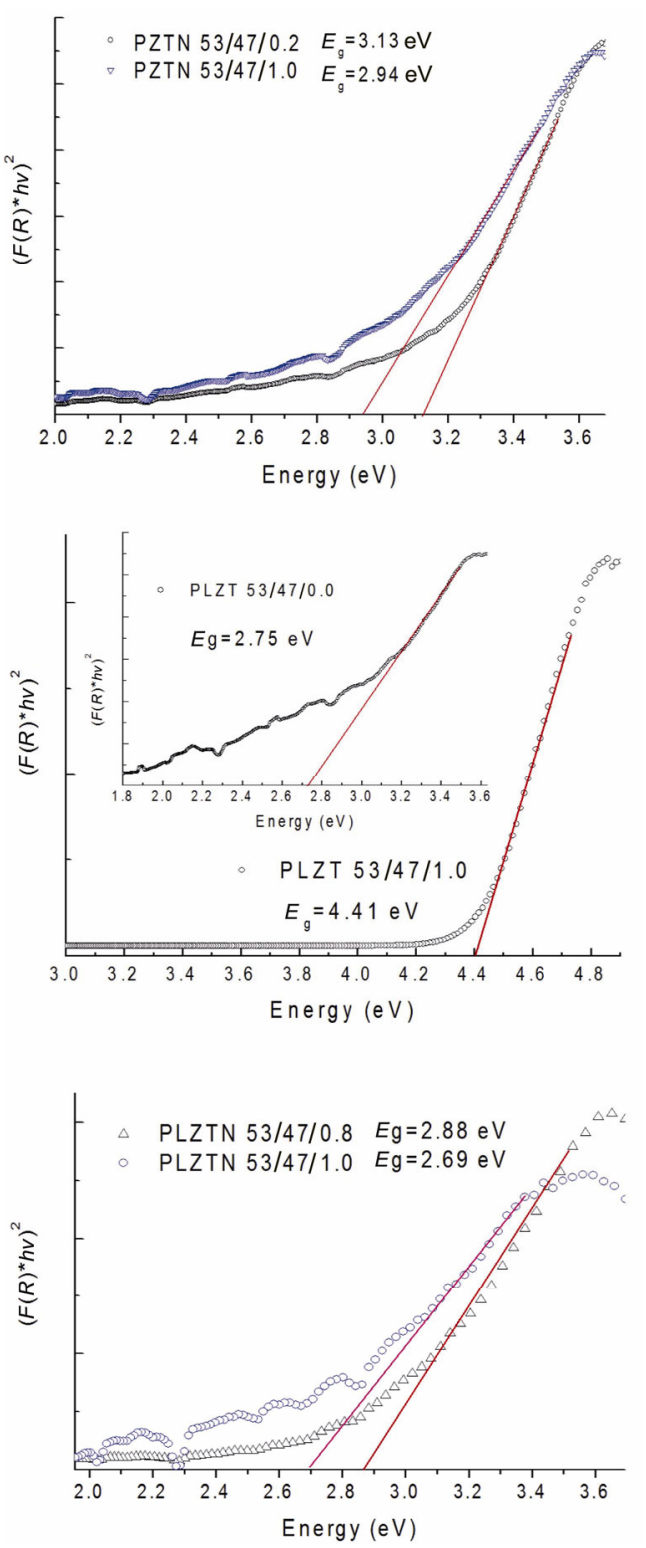

Fig. 7 Tauc plot for PZTN, PLZT, and PLZTN systems with different dopant concentration, assuming direct band gap.

density of states above Fermi level has a strong contribution from La- $4 \mathrm{f}$ orbital, and then the increase of the band gap energy with an increased concentration of $\mathrm{La}$ is influenced by La-4f and $\mathrm{O}-2 \mathrm{p}$ orbital hybridization [22].

According to Eyraud et al. [24,25], singly and doubly ionized vacancies of lead and oxygen coexist in the PZT ceramic, thus they may constitute donor and acceptor sites which are able to exchange electrons according to the following reactions:

$$
\begin{aligned}
& \mathrm{V}_{\mathrm{Pb}} \rightarrow \mathrm{V}_{\mathrm{Pb}}^{\prime}+\mathrm{e} \\
& \mathrm{V}_{\mathrm{Pb}}^{\prime} \rightarrow \mathrm{V}_{\mathrm{Pb}}^{\prime \prime}+\mathrm{e}
\end{aligned}
$$

$$
\begin{aligned}
& \mathrm{V}_{\mathrm{O}} \rightarrow \mathrm{V}_{\mathrm{O}}^{\prime}+\mathrm{e} \\
& \mathrm{V}_{\mathrm{O}}^{\prime} \rightarrow \mathrm{V}_{\mathrm{O}}^{\prime \prime}+\mathrm{e}
\end{aligned}
$$

In accordance with these results, it is possible that at least three types of defects coexist in PZTN $\mathrm{V}_{\mathrm{Pb}}^{\prime}$, $\mathrm{V}_{\mathrm{Pb}}^{\prime \prime}$, and $\mathrm{V}_{\mathrm{O}}^{\prime}$, and all types of defects coexist in PLZT and PLZTN $\mathrm{V}_{\mathrm{Pb}}^{\prime}, \mathrm{V}_{\mathrm{Pb}}^{\prime \prime}, \mathrm{V}_{\mathrm{O}}^{\prime}$, and $\mathrm{V}_{\mathrm{O}}^{\prime \prime}$, whose contribution to PL depends on the defect concentration and the energy level in the band gap.

In both thermal processes during ceramic synthesis, calcination and sintering stages, lead can be lost from the ceramic material, due to its high volatility, which provides both fully-ionized cationic lead $\mathrm{V}_{\mathrm{Pb}}^{\prime \prime}$ vacancies and anionic oxygen vacancies $\mathrm{V}_{\mathrm{O}}^{\prime \prime}$. On the other hand, following Eyraud's model [25], the valences of the niobium and lanthanum are assumed as donor dopants, which have a strong influence in the ionization state of extrinsic lead and oxygen vacancies in PZT. The emission intensity of this band also shows a strong dependence on dopant concentration, but is present in all compositions indicating different defect types related to a deep level inside the band gap. In general, the incorporation of $\mathrm{Nb}^{5+}$ increases the PL intensity in this region due to the compensation of charge and induced defects $\left(\mathrm{V}_{\mathrm{Pb}}^{\prime}\right.$ and $\left.\mathrm{V}_{\mathrm{Pb}}^{\prime \prime}\right)$. However, the incorporation of $\mathrm{La}^{3+}$ decreases the PL intensity of the band but increases the width due to the compensation of charge and induced defects $\left(\mathrm{V}_{\mathrm{Pb}}^{\prime}, \mathrm{V}_{\mathrm{Pb}}^{\prime \prime}, \mathrm{V}_{\mathrm{O}}^{\prime}\right.$, and $\mathrm{V}_{\mathrm{O}}^{\prime \prime}$ ), as it was already seen previously.

For PZTN, the higher intensity observed for band at $2.56 \mathrm{eV}$ rather than band around $1.73 \mathrm{eV}$ is an indication that the oxygen vacancy concentration is higher than lead vacancies. However, the peak at 1.73 $\mathrm{eV}$ for PLZT and PLZTN is smaller than the peak for PZTN; this indicates that the concentration of lead vacancies in PLZT and PLZTN is higher than for PZTN. In principle, the incorporation of $\mathrm{La}^{3+}$ and $\mathrm{Nb}^{5+}$ in PZT samples would produce more lead vacancies than oxygen vacancies; this does not happen when the sample is doped alone with $\mathrm{Nb}$. The simultaneous disorder of lead and oxygen vacancies should be created during the sintering process [26]. Table 4 shows the emission power in the studied samples when they are excited with 273,373 , and $457 \mathrm{~nm}$.

The results of the band gap energy agree with the results presented in previous experimental and theoretical results $[5,6,27]$.

In these samples, the PZTN and PLZTN systems show a variation around 0.38 and $0.42 \mathrm{eV}$ respectively with dopant concentration; nevertheless, the PLZT 
Table 4 Emission power in each PZT system with dopant concentration of $1.0 \mathrm{~mol} \%$, excited with 273 , 373 , and $457 \mathrm{~nm}$; for each excitation band the power incident is also measured. The power shown is the sum of all powers present with that excitation because the detector is not selective in wavelength

\begin{tabular}{cccccc}
\hline \multirow{2}{*}{$\lambda_{\text {exc }}(\mathrm{nm})$} & \multicolumn{5}{c}{ Power emission $(\mathrm{mW})$} \\
\cline { 2 - 6 } & PZT & PLZT & PZTN & PLZTN & Lamp \\
\hline 273 & $0.03 \times 10^{-3}$ & $0.04 \times 10^{-3}$ & $0.02 \times 10^{-3}$ & $0.01 \times 10^{-3}$ & $0.49 \times 10^{-3}$ \\
373 & 2.45 & 3.69 & 1.08 & 1.24 & 29.7 \\
457 & 5.60 & 8.01 & 2.76 & 3.21 & 75.7 \\
\hline
\end{tabular}

shows a great variation in the band gap with dopant concentration (see Table 3). The effect of lanthanum incorporation increases the band gap energy from $2.75 \mathrm{eV}$ for pure PZT until $4.41 \mathrm{eV}$ for higher concentration. It is known that $\mathrm{ABO}_{3}$ perovskite structure presents a mixture of chemical type bonds, and the sequence $\mathrm{O}-\mathrm{B}-\mathrm{O}$ has a covalent character and gives place to the anion $\left[\mathrm{BO}_{6}\right]^{2-}$. On the other hand, there is an ionic character between this anion and the cation $\mathrm{A}^{2+}$. The incorporation of $\mathrm{La}^{3+}$ increases the ionic character among their neighbor atoms and also increases the covalent character bond of the perovskite structure [28].

\section{Conclusions}

A narrow relationship between the structural phase and PL intensity is observed. For the samples doped with $\mathrm{Nb}^{5+}$ prevalence of tetragonal phase, PL emission bands are obtained with intensities one or two orders superior to samples doped with $\mathrm{La}^{3+}$ where the rhombohedral phase prevails. PL spectra suggest that PZTN samples have higher concentration of oxygen and lead vacancies than other samples, which accentuate the decrease of the band gap. The main PL emissions are observed around 1.76-1.87 eV and 2.5-2.66 eV excited with 457, 373, and $273 \mathrm{~nm}$.

PZTN and PLZTN show a variation of 0.38 and $0.42 \mathrm{eV}$ respectively in the band gap energy $E_{\mathrm{g}}$, with dopant concentration, while PLZT shows a great variation in $E_{\mathrm{g}}$ with $\mathrm{La}^{3+}$ concentration. The local minimum in $E_{\mathrm{g}}$ coincides in the three group samples for $0.6 \mathrm{~mol} \%$ dopant concentration. The emission results suggest that the PZTN ceramic is a potential material for applications in optoelectronic devices.

\section{Acknowledgements}

This research was supported by project PNCB 10/09,
Cuba, the Sabbatical program and projects CB 240460 and (LIDTRA) LN2015-254119 of CONACYT Mexico. M. D. Durruthy acknowledges the Physics Mexican Society for facilitating her visit to CINVESTAV-Querétaro by Mexico, Central America and the Caribbean Programs for the Advance of the Science, the Technology and the Innovation, CONACYT-ICTP-SMF. The technical assistance of Ing. M. Landaverde and M.Sc. R. Flores-Farías is acknowledged. The authors dedicate this work and thank posthumously the comments and suggestions of Dr. Francisco Espinoza Beltran.

\section{References}

[1] A-Paz de Araujo C, Cuchiaro JD, McMillan LD, et al. Fatigue-free ferroelectric capacitors with platinum electrodes. Nature 1995, 374: 627-629.

[2] Park BH, Kang BS, Bu SD, et al. Lanthanum-substituted bismuth titanate for use in non-volatile memories. Nature 1999, 401: 682-684.

[3] Chon U, Jang HM, Kim MG, et al. Layered perovskites with giant spontaneous polarizations for nonvolatile memories. Phys Rev Lett 2002, 89: 087601.

[4] Warusawithana MP, Cen C, Sleasman CR, et al. A ferroelectric oxide made directly on silicon. Science 2009, 324: 367-370.

[5] Silva MS, Cilense M, Orhan E, et al. The nature of the photoluminescence in amorphized PZT. $J$ Lumin 2005, 111: 205-213.

[6] Longo E, de Figueiredo AT, Silva MS, et al. Influence of structural disorder on the photoluminescence emission of PZT powders. J Phys Chem A 2008, 112: 8953-8957.

[7] Sun CQ, Jin D, Zhou J, et al. Intense and stable blue-light emission of $\mathrm{Pb}\left(\mathrm{Zr}_{x} \mathrm{Ti}_{1-x}\right) \mathrm{O}_{3}$. Appl Phys Lett 2001, 79: 10821084.

[8] Bao D. Photoluminescence in low-dimensional oxide ferroelectric materials. In: Ferroelectrics. Coondoo I, Ed. InTech, 2010: 43-62.

[9] Durruthy-Rodríguez MD, Costa-Marrero J, Hernández-García $\mathrm{M}$, et al. Photoluminescence in "hard" and "soft" ferroelectric ceramics. Appl Phys A 2010, 98: 543-550.

[10] Durruthy-Rodríguez MD, Costa-Marrero J, Hernández-Garcia $\mathrm{M}$, et al. Optical characterization in $\mathrm{Pb}\left(\mathrm{Zr}_{1-x} \mathrm{Ti}_{x}\right)_{1-y} \mathrm{Nb}_{y} \mathrm{O}_{3}$ ferroelectric ceramic system. Appl Phys A 2011, 103: 467476.

[11] Kottim G. Reflectance Spectroscopy. New York: Springer Verlag, 1969.

[12] Baedi J, Hosseini SM, Kompany A. The effect of excess titanium and crystal symmetry on electronic properties of $\mathrm{Pb}\left(\mathrm{Zr}_{1-x} \mathrm{Ti}_{x}\right) \mathrm{O}_{3}$ compounds. Comput Mater Sci 2008, 43: 909-916.

[13] López R, Gómez R. Band-gap energy estimation from diffuse reflectance measurements on sol-gel and commercial 
$\mathrm{TiO}_{2}$ : A comparative study. J Sol-Gel Sci Technol 2012, 61: $1-7$.

[14] Teixeira GF, Zaghete MA, Gasparotto G, et al. Photoluminiscence properties and synthesis of a PZT mesostructure obtained by the microwave-assisted hydrothermal method. J Alloys Compd 2012, 512: 124 127.

[15] Yu PY, Cardona M. Fundamentals of Semiconductors Physics and Materials Properties. Springer-Verlag Berlin Heidelberg, 2001: 268-280.

[16] Noheda B, Cox DE, Shirane G, et al. Stability of the monoclinic phase in the ferroelectric perovskite $\mathrm{PbZr}_{1-x} \mathrm{Ti}_{x} \mathrm{O}_{3}$. Phys Rev B 2000, 63: 014103.

[17] Jaffe B, Roth RS, Marzullo S. Piezoelectric properties of lead zirconate-lead titanate solid-solution ceramics. $J$ Appl Phys 1954, 25: 809-810.

[18] Noheda B, Gonzalo JA, Cross LE, et al. Tetragonal-tomonoclinic phase transition in a ferroelectric perovskite: The structure of $\mathrm{PbZr}_{0.52} \mathrm{Ti}_{0.48} \mathrm{O}_{3}$. Phys Rev B 2000, 61: 8687-8695.

[19] Liu Y, Xu C-N, Nonaka K, et al. Photoluminescence and triboluminescence of PZT materials at room temperature. Ferroelectrics 2001, 264: 331-336.

[20] Baedi J, Benam MR, Majidiyan M. First-principles study of the effect of La substitution on the electronic and optical properties of $\mathrm{Pb}\left(\mathrm{Zr}_{x} \mathrm{Ti}_{1-x}\right) \mathrm{O}_{3}$ crystal. Phys Scr 2010, 81: 035701.

[21] Santos IA, Endo C, Zanin AL, et al. Hot-pressed transparent PLZT ceramics from low cost chemical processing. Mat Res 2001, 4: 291-295.
[22] Stashans A, Maldonado F. A quantum mechanical study of La-doped $\mathrm{Pb}(\mathrm{Zr}, \mathrm{Ti}) \mathrm{O}_{3}$. Physica B 2007, 392: 237-241.

[23] Anicete-Santos M, Silva MS, Orhan E, et al. Contribution of structural order-disorder to the room-temperature photoluminescence of lead zirconate titanate powders. $J$ Lumin 2007, 127: 689-695.

[24] Eyraud L, Guiffard B, Lebrun L, et al. Interpretation of the softening effect in PZT ceramics near the morphotropic phase boundary. Ferroelectrics 2006, 330: 51-60.

[25] Eyraud L, Eyraud P, Lebrun L, et al. Effect of (Mn, F) co-doping on PZT characteristics under the influence of external disturbances. Ferroelectrics 2002, 265: 303-316.

[26] Dixit A, Majumder SB, Katiyar RS, et al. Studies on the relaxor behavior of sol-gel derived $\mathrm{Ba}\left(\mathrm{Zr}_{x} \mathrm{Ti}_{1-x}\right) \mathrm{O}_{3}(0.30 \leqslant$ $x \leqslant 0.70)$ thin films. J Mater Sci 2006, 41: 87-96.

[27] Baedi J, Hosseini SM, Kompany A. The effect of excess titanium and crystal symmetry on electronic properties of $\mathrm{Pb}\left(\mathrm{Zr}_{1-x} \mathrm{Ti}_{x}\right) \mathrm{O}_{3}$ compounds. Comput Mater Sci 2008, 43: 909-916.

[28] Casabó i Gispert J. Atomic structure and chemical bond. Reverté SA, Ed. Barcelona: Ep-15.4.2-Lattice perovskite type, 344-345.

Open Access The articles published in this journal are distributed under the terms of the Creative Commons Attribution 4.0 International License (http://creativecommons.org/licenses/by/4.0/), which permits unrestricted use, distribution, and reproduction in any medium, provided you give appropriate credit to the original author(s) and the source, provide a link to the Creative Commons license, and indicate if changes were made. 